Asian-Australasian Journal of

Bioscience and Biotechnology

ISSN 2414-1283 (Print) 2414-6293 (Online)

www.ebupress.com/journal/aajbb

\title{
Article \\ Tradition of raw milk consumption and its health impact among people living in the coastal regions of Bangladesh
}

\author{
S. M. Tanvir Reza ${ }^{1}$, Wahedul Karim Ansari ${ }^{1}$, Md Robiul Karim² ${ }^{2}$, A.K.M. Mostafa Anower ${ }^{1}$ and Farzana Islam \\ Rume $^{1, *}$
}

${ }^{1}$ Department of Microbiology and Public Health, Faculty of Animal Science and Veterinary Medicine, Patuakhali Science and Technology University, Barisal, Bangladesh

${ }^{2}$ Department of Medicine, Faculty of Veterinary Medicine and Animal Science, Bangabandhu Sheikh Mujibur Rahman Agricultural University, Gazipur 1706, Bangladesh

*Corresponding author: Farzana Islam Rume, Professor, Department of Microbiology and Public Health, Faculty of Animal Science and Veterinary Medicine, Patuakhali Science and Technology University, Barisal, Bangladesh. Phone: +8801711226056; E-mail: farzanarume@ pstu.ac.bd

Received: 11 March 2021/Accepted: 19 April 2021/ Published: 30 April 2021

\begin{abstract}
Milk is a nutrient-rich liquid food for human and animals. However, owing to its complex biochemical structure and high water activity, it serves as an outstanding microorganism growth medium under suitable conditions. People in Bangladesh's coastal areas have a lifestyle and tradition that includes drinking raw milk for nutrition or as an energy drink, which presents a health risk to them. The present cross-sectional study was carried out to determine the reasons for drinking raw milk in coastal areas, as well as the public health impact of doing so. A total of 100 respondents were interviewed and subsequently, milk samples were collected for quality testing through methylene blue reduction test (MBRT). Among 100 respondent 70 were consumers and 30 were farmers. Results showed that the samples of farmers were better than that of consumers. The majority of raw milk consumers were male who thought raw milk was more nutritious than heat-treated milk. Furthermore, the majority of them were professionally engaged in farming. Both consumers and farmers had less educational qualifications, managed their cattle in dirty environments, practiced extensive grazing system on communal grazing areas and around one fourth of them vaccinated their animals. Furthermore, the findings revealed that $40 \%$ of respondents were between the ages of 35 and 45 , with $62 \%$ reporting no health complications as a result of drinking raw milk and the remainder reporting mainly gastrointestinal problems. According to the findings of this report, the quality of raw cow milk was poor; unhygienic practices and poor animal husbandry at farm level predisposed farmers, consumers and the public to risk of contracting milk-borne infections and associated bacterial resistances. It is recommended that veterinarians, extension officers and all stakeholders should play their roles in ensuring safe quality milk supply to consumers.
\end{abstract}

Keywords: raw milk drinking; coastal culture; health hazard

\section{Introduction}

Milk is an important source of nutrients to human and animals, as well as the sole food for off spring of mammals before they are able to eat and digest other types of food. It provides all of the essential and digestible components for the construction and maintenance of the human and animal bodies in a healthy manner (Pandey and Voskuil, 2011).

Despite their high nutritional value, milk and milk byproducts can serve as excellent growth media for a variety of microrganisms due to their unique composition and properties (Mushfia et al., 2015; Nada et al., 2012). Microbes that may be present in milk can include pathogens, spoilage organisms and organisms that may be conditionally beneficial e.g., lactic acid bacteria (Kathryn et al., 2017). The presence of pathogenic 
microorganisms commonly isolated from milk and milk products has arisen as a significant threat to human health (Hasan et al., 2015).

Several studies have described a number of bacteria that cause milk-borne diseases, including Brucella spp, Campylobacter jejuni, Bacillus cereus, Shiga toxin-producing E. coli (E.coli O157:H7), Coxiellaburnetii, Listeria monocytogenes, Mycobacterium tuberculosis, Mycobacterium bovis, Mycobacterium avium subspecies paratuberculosis, Salmonella spp, Yersinia enterocolitica, and certain strains of Staphylococcus aureus (Revathi et al., 2012; Al-Tahiri, 2005; Sivapalasingams et al., 2004; Shirima et al., 2003).

Pathogen contamination of raw milk can occur in one of four ways: direct passage from the cow's blood into the milk (systemic infection), mastitis (udder infection), fecal contamination (external contamination of milk from the environment during or after milking), or contamination from human skin or milking apparatus (John, 2015; Oliver et al., 2005). The consumption of this contaminated raw milk may lead to food-borne diseases (FBDs) (Nathaly et al., 2017). Food borne diseases are of great concern around the world. This is an important issue in developing countries where poor sanitation is maintained during collection and processing of milk from cattle and buffaloes (Le, 2003).

The coastal region of Bangladesh is geomorphologically and hydrologically dominated by the Ganges Brahmaputra Meghna (GBM) river system and the Bay of Bengal. The coastal belt occupiesnearly 47,201 km2, or $32 \%$ of the country and is home to approximately 35 million people (Hafez, 2019). The majority of the people who live there are subsistence farmers who depend primarily on livestock and fisheries. Their socioeconomic situation is not conducive to schooling and social awareness. As a result, the area fosters a number of misconceptions, one of which is the drinking raw milk, which has significant public health consequences. Many of the uneducated or undereducated coastal residents have developed a taste for raw cow, goat, and buffalo milk. Raw milk is also used to make a variety of milk products, which are sold at local markets. Various myths that have been passed on from ancestral times serve as stimulant for the habit of drinking raw milk. This phenomenon is considered to be a significant vehicle for the transmission of milk-borne pathogens to humans. Raw milk, on the other hand, can pose a significant health risk to consumers due to antimicrobial residues, in addition to being a possible carrier of pathogens (Kivaria et al., 2006; Omore et al., 2005).

Antibiotic residues are remnants or small amounts of antimicrobial drugs or their active metabolites which remain in milk after treating lactating cows (Abebew et al., 2014; Anakalo and Ase, 2004). Antibiotics are commonly used in dairy cattle for curative and preventive purposes of different bacterial and associated infections (Abebew et al., 2014; Sharma et al., 2011). Inappropriate use of these antibiotics may lead to various bacterial pathogens developing resistance to most commonly used antibiotics which in turn increases bacterial resistant to almost all existing antibiotics (Sharma et al., 2011). The outcome of random use of antimicrobial agents in animals is expansion of antimicrobial resistant bacteria that may be transferred from animals to humans through contact, contaminated environment or milk and milk products (Abebew et al., 2014; Sharma et al., 2011).

The present study was designed to evaluate the microbial content of raw cow's milk as well as the public health risk associated with conventional raw milk intake in Bangladesh's coastal regions.

\section{Materials and Methods}

\subsection{Study area}

The study was conducted between January and June 2018 in different areas of Bangladesh's coastal belt, including Barisal, Bhola, Patuakhali, Jhalokathi, Pirojpur and Barguna.The area is crisscrossed by several rivers and traditional lifestyles.

\subsection{Survey and sample collection}

A total of 100 milk samples were obtained from participants who were chosen at random. In the case of consumers, a single sample was obtained, while in the case of framers or milkers, several samples were collected. Immediately after collection in falcon tubes, the samples were undergone Methylene Blue Reductase Test (MBRT) for qualitative analysis. For the collection of relevant data from consumers and farmers/milkers/marketers, two separate questionnaires were developed based on personal, socioeconomic, and output group. The survey included selected participants who had consumed raw milk at least once in their lives, and there were many farmers who regularly consumed raw milk. The sample included 70 customers and 30 farmers who met the questionnaire criteria. 


\subsection{Quality test of the sample (MBRT)}

Nine $\mathrm{ml}$ of the each sample was taken into a falcon tube and one $\mathrm{ml}$ of methylene blue solution was added and then the mixture was kept in a test-tube rack to observe the following results:.

1. Reduction within 30 minutes: Very poor quality

2. Reduction occurring between 30 minutes and 2 hours : Poor quality

3. Reduction occurring between 2 and 6 hours: Fair quality

4. Reduction occurring between 6 and 8 hours: Good quality

5. Not reduced in 8 hours: Excellent quality

\subsection{Statistical analysis}

Data were computerized using Microsoft Excel and transferred to Software SPSS for statistical analysis.

\section{Results and Discussion}

\subsection{Methylene blue reduction test of consumer samples}

Methylene blue reduction test (MBRT) was performed on 70 consumer milk samples and the results revealed that $30 \%$ (21/70) of the samples were very poor in quality because their reduction time was less than 1 hour (Table 1). It was also observed that $57.14 \%(40 / 70)$ of the samples were poor in quality (reduction time $\leq 2$ hours), $12.85 \%(8 / 70)$ were fair (reduction time $\leq 3$ hours) and just one sample was good in quality since its reduction time was less than 4 hours.

The MBRT test on 30 framer milk samples showed that $73.33 \%$ (22/30) of the samples were fair in quality since their reduction time was less than 3 hours (Table 2). While none of the samples was very poor, only seven samples were good in quality. The current results are comparable to other scientific reports who classified milk as poor when reduced for less than half an hour and good when reduced for 3 to 4 hours (Padma and Priyanka, 2012 and Yirsaw, 2004). In the tropical area, Tahmina et al., 2013 classified raw milk as good or very good based on MBRT reduction period of less than or more than 5 hours.

\subsection{Comparison of MBRT results between consumer and farmer milk samples}

Figure 1 shows a comparison of MBRT findings from customer and farmer milk samples, showing that raw milk at the consumer level was more contaminated than raw milk at the farm level. This quality test indicates that raw milk at consumer level poses serious public health concern. This conclusion is backed up by the findings of a number of other researchers who investigated some factors and handling practices of raw milk contamination from producers to consumer's level and stated hazardous for human consumption (Orwa et al., 2016; Swai and Schoonman, 2011).

\subsection{Comparison of educational backgrounds of raw milk consumers and farmers}

Table 3 shows that $38.57 \%$ (27/70) of the consumers had a primary education, while $41.43 \%(29 / 70)$ had a secondary education. Among the farmers, $40 \%(12 / 30)$ were educated at primary level and $30 \%(9 / 30)$ were at secondary level. In both the categories, only about $6 \%$ of the participants completed higher education. As of Table 3, the majority of consumers and farmers had little educational qualification, which was a problem since they were less aware of health risks associated with dinking raw milk. There were a few educated people who drank raw milk because of a local myth and curiosity.

\subsection{Comparison of raw milk consumers' and farmers' occupations}

According to Table 4, majority of the target participants of raw milk consumers and farmers were engaged in agriculture and livestock farming. In consumers group, 38.57\% (27/70) were involved in agriculture and $17.14 \%$ $(12 / 70)$ in livestock. Similarly in farmers group, $23.33 \%$ (7/30) were engaged in agriculture sector and 56.67\% (17/30) in livestock sector. This data is strikingly similar to the previous study by International Farm Comparison Network, 2004, in which the authors have identified how subsistence farmer groups typically ingest milk in the form of fresh milk. 


\subsection{Age and gender comparison of raw milk consumer and farmer}

Table 5 shows that most of the raw milk consumers and farmers were between the ages of 35 and 45 . Interestingly, this finding corresponds to a previous study by Gerard and Stephen, 2014, who also identified raw milk consumers in this age range. Lower number of female than male participants consumed raw milk. Females were less interested in drinking raw milk than males. Previous research by Angela and Paul, 2012 and Food Standard Agency, 2018 demonstrated that females are less involved in consuming raw milk than males, which is consistent with our current results.

\subsection{Possible reasons of having raw milk}

The consumers were provided a questionnaire containing an open question about the reason of drinking raw milk. According to the responses showed in Figure 2,79\% of consumers believe that raw milk is more nutritious than heat processed or pasteurized milk. Raw milk is thought to provide immediate nutrition by $11 \%$ of consumers, and it is thought to increase sexual capacity by just $3 \%$ of consumers. Previous researches by Gerard and Stephen, 2014 and Hegarty et al., 2002 suggest that customers drink raw milk on a regular basis for its higher nutritional value than processed milk. However they also edited tradition as important component for this behave.

\subsection{Complications reported after drinking raw milk}

As seen in Figure 3, interestingly, $62 \%$ of participants reported no complications after drinking raw milk, while the remaining 38\% reported having a medical condition. The main explanation for this is that there is less risk of contamination if farmers consume raw milk right after milking. The method of getting raw milk from seller to consumer, on the other hand, entails measures that can contaminate the milk.

There have been various medical problems recorded as a result of drinking raw milk, including diarrhea, vomiting, abdominal pain, fever, headache, body ache, and so on (Figure 4). Several researchers, including Jayarao et al., 2006 and Oliver et al., 2005 have suggested that pathogenic bacteria of human health importance can be present in raw milk, mostly causing gastroenteritis but sometimes contributing to septicemia and meningitis in immunocompromised patients.

\subsection{Correlation between milk contamination and animal husbandry practices}

Contamination of raw milk is primarily determined by demography, animal condition, and farming method. The following conditions were taken into account:

\subsubsection{Vaccination}

Figure 5 indicates that the majority of farmers or producers $(77 \%)$ did not undergo vaccine operations, and therefore the raw milk from that farm was highly hazardous for human consumption. According to Erica et al., 2007 , milk can become contaminated in a variety of ways. In the event of a systemic infection or mammary gland infection, a pathogen may be transmitted to raw milk, posing a public health risk.

\subsubsection{Diseases history}

Figure 6 shows that the animals of the farmers had a number of disease problems which posed significant complications after drinking of raw milk. According to Verraes et al., 2015, a large number of unhygienic procedures are applied during storage and transportation which are major sources of contamination at the consumer level. It is worth mentioning that raw milk is a known vehicle for various pathogens, including Escherichia coli, Mycobacterium bovis, Listeria monocytogenes and species of Campylobacter, Brucella, Salmonella. Therefore, proper milking, cleaning and sanitizing procedures of equipments and environments are essential tool to ensure quality of milk. Many countries have implemented laws and regulations concerning the composition and hygienic quality of milk and milk products to protect both the consumers and the public health (Pandey and Voskuil, 2011). Unfortunately, these laws and regulations are not often adhered in developing countries making milk-borne diseases a significant health risk to public. 
Asian Australas. J. Biosci. Biotechnol. 2021, 6 (1)

Table 1. MBRT test results for 70 consumer milk samples.

\begin{tabular}{|c|c|c|c|c|c|c|c|c|c|}
\hline \multirow{2}{*}{$\begin{array}{l}\text { Sample } \\
\text { No. }\end{array}$} & \multicolumn{4}{|c|}{ Methyline blue Reduction Time } & \multirow{2}{*}{$\begin{array}{l}\text { Sample } \\
\text { No. }\end{array}$} & \multicolumn{4}{|c|}{ Methyline blue Reduction Time } \\
\hline & $\leq 1 \mathrm{hr}$ & $\leq 2 \mathrm{hr}$ & $\leq 3 \mathrm{hr}$ & $\geq 4 \mathrm{hr}$ & & $\leq 1 \mathrm{hr}$ & $\leq 2 \mathrm{hr}$ & $\leq 3 \mathrm{hr}$ & $\leq 4 \mathrm{hr}$ \\
\hline 1 & 1 & & & & 36 & 1 & & & \\
\hline 2 & & 1 & & & 37 & 1 & & & \\
\hline 3 & & 1 & & & 38 & & 1 & & \\
\hline 4 & & 1 & & & 39 & & 1 & & \\
\hline 5 & & & 1 & & 40 & & 1 & & \\
\hline 6 & & & 1 & & 41 & & 1 & & \\
\hline 7 & & 1 & & & 42 & & & 1 & \\
\hline 8 & & 1 & & & 43 & & 1 & & \\
\hline 9 & & & 1 & & 45 & & 1 & & \\
\hline 10 & & 1 & & & 46 & & 1 & & \\
\hline 11 & & 1 & & & 47 & & 1 & & \\
\hline 12 & & 1 & & & 48 & & 1 & & \\
\hline 13 & & 1 & & & 49 & 1 & & & \\
\hline 14 & & 1 & & & 50 & 1 & & & \\
\hline 15 & & 1 & & & 51 & & 1 & & \\
\hline 16 & & & 1 & & 52 & 1 & & & \\
\hline 17 & 1 & & & & 53 & 1 & & & \\
\hline 18 & 1 & & & & 54 & 1 & & & \\
\hline 19 & & 1 & & & 55 & 1 & & & \\
\hline 20 & & 1 & & & 56 & & 1 & & \\
\hline 21 & & 1 & & & 57 & & 1 & & \\
\hline 22 & 1 & & & & 58 & & 1 & & \\
\hline 23 & 1 & & & & 59 & & & & \\
\hline 24 & 1 & & & & 60 & & & 1 & \\
\hline 25 & & 1 & & & 61 & & 1 & & \\
\hline 26 & 1 & & & & 62 & & 1 & & \\
\hline 27 & & 1 & & & 63 & & 1 & & \\
\hline 28 & & 1 & & & 64 & & & & 1 \\
\hline 29 & & 1 & & & 65 & & 1 & & \\
\hline 30 & & 1 & & & 66 & & 1 & & \\
\hline 31 & 1 & & & & 67 & & 1 & & \\
\hline 32 & 1 & & & & 68 & 1 & & & \\
\hline 34 & 1 & & & & 69 & 1 & & & \\
\hline 35 & & 1 & & & 70 & 1 & & & \\
\hline TOTAL & & & & & & $21(30 \%)$ & $40(57.14 \%)$ & $8(12.85 \%)$ & 1 \\
\hline
\end{tabular}

Table 2. MBRT test results for 30 farmers' milk samples.

\begin{tabular}{|c|c|c|c|c|c|c|c|c|c|}
\hline \multirow{2}{*}{$\begin{array}{l}\text { Sample } \\
\text { No. }\end{array}$} & \multicolumn{4}{|c|}{ Methyline blue Reduction Time } & \multirow{2}{*}{$\begin{array}{l}\text { Sample } \\
\text { No. }\end{array}$} & \multicolumn{4}{|c|}{ Methyline blue Reduction Time } \\
\hline & $\leq 1 \mathrm{hr}$ & $\leq \mathbf{2 h r}$ & $\leq 3 \mathrm{hr}$ & $\geq 4 \mathrm{hr}$ & & $\leq 1 \mathrm{hr}$ & $\leq \mathbf{2 h r}$ & $\leq 3 \mathrm{hr}$ & $\leq 4 \mathrm{hr}$ \\
\hline 1 & & & & 1 & 16 & & & 1 & \\
\hline 2 & & & & 1 & 17 & & & 1 & \\
\hline 3 & & & 1 & & 18 & & & 1 & \\
\hline 4 & & & & 1 & 19 & & & 1 & \\
\hline 5 & & & & 1 & 20 & & & & 1 \\
\hline 6 & & & & 1 & 21 & & & 1 & \\
\hline 7 & & & 1 & & 22 & & & 1 & \\
\hline 8 & & & 1 & & 23 & & & 1 & \\
\hline 9 & & & 1 & & 24 & & & 1 & \\
\hline 10 & & & 1 & & 25 & & & 1 & \\
\hline 11 & & & 1 & & 26 & & & & 1 \\
\hline 12 & & 1 & & & 27 & & & 1 & \\
\hline 13 & & & 1 & & 28 & & & 1 & \\
\hline 14 & & & 1 & & 29 & & & 1 & \\
\hline 15 & & & 1 & & 30 & & & 1 & \\
\hline TOTAL & & & & & & NIL & $01(3.33 \%)$ & $22(73.33 \%)$ & $07(14.28 \%)$ \\
\hline
\end{tabular}


Table 3. Educational backgrounds of raw milk consumers and farmers.

\begin{tabular}{|l|l|l|l|l|}
\hline Survey Class & Primary & Secondary & College & More \\
\hline Consumer $(70)$ & $27(38.57 \%)$ & $29(41.43 \%)$ & $10(14.28 \%)$ & $04(5.71 \%)$ \\
\hline Farmer $(30)$ & $12(40 \%)$ & $09(30 \%)$ & $07(23.33 \%)$ & $02(6.67 \%)$ \\
\hline
\end{tabular}

Table 4. Occupation of raw milk consumers and farmers.

\begin{tabular}{|l|l|l|l|l|}
\hline Survey Class & Agriculture & Livestock & Service & Business \\
\hline Consumer $(70)$ & $27(38.57 \%)$ & $12(17.14 \%)$ & $17(24.28 \%)$ & $14(20)$ \\
\hline Farmer $(30)$ & $07(23.33 \%)$ & $17(56.67 \%)$ & $01(3.33 \%)$ & $05(16.67 \%)$ \\
\hline
\end{tabular}

Table 5. Age and gender of raw milk consumers and farmers.

\begin{tabular}{|l|l|l|l|l|l|l|}
\hline Survey Class/Age range & $\mathbf{1 5 - 2 5}$ & $\mathbf{2 5 - 3 5}$ & $\mathbf{3 5 - 4 5}$ & $\mathbf{4 5}$ & Male & Female \\
\hline Consumer (70) & 17 & 16 & 23 & 14 & 59 & 11 \\
\hline Farmer (30) & 02 & 04 & 17 & 07 & 29 & 01 \\
\hline
\end{tabular}

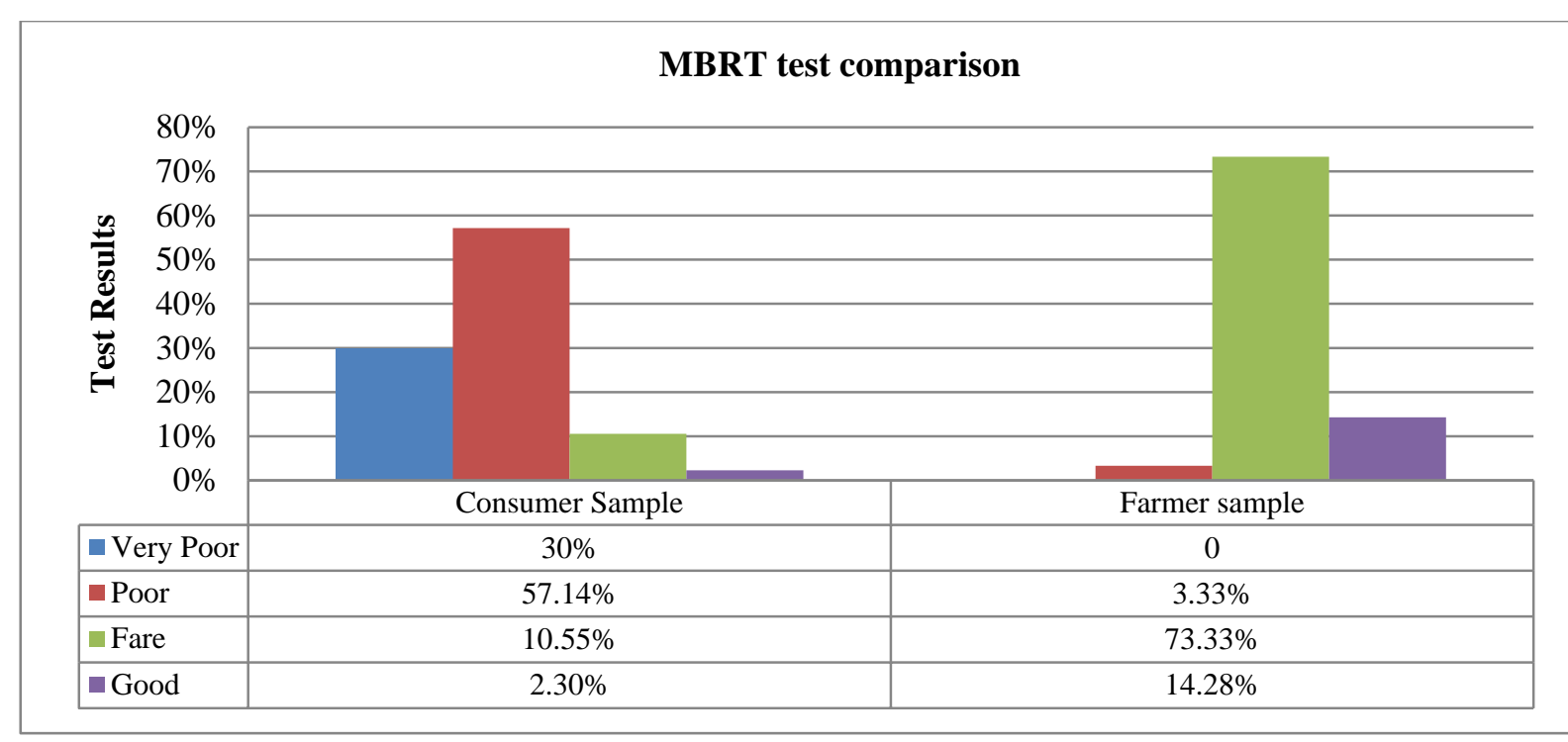

Figure 1. Comparison of MBRT results between consumer and farmer milk samples.

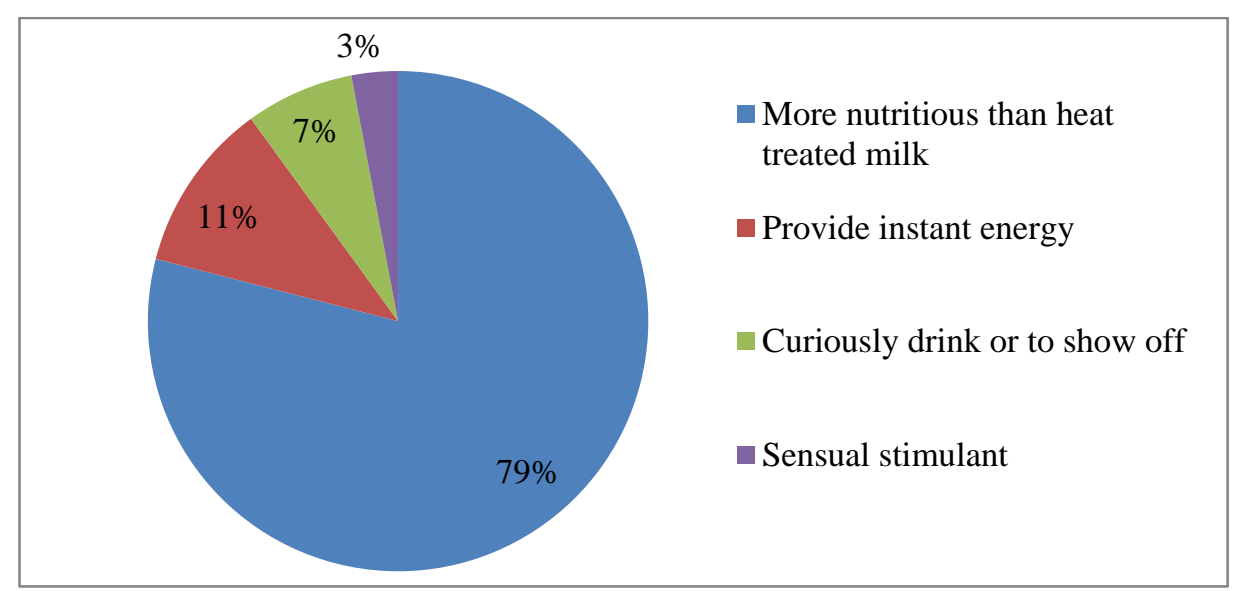

Figure 2. The reasons of having raw milk. 


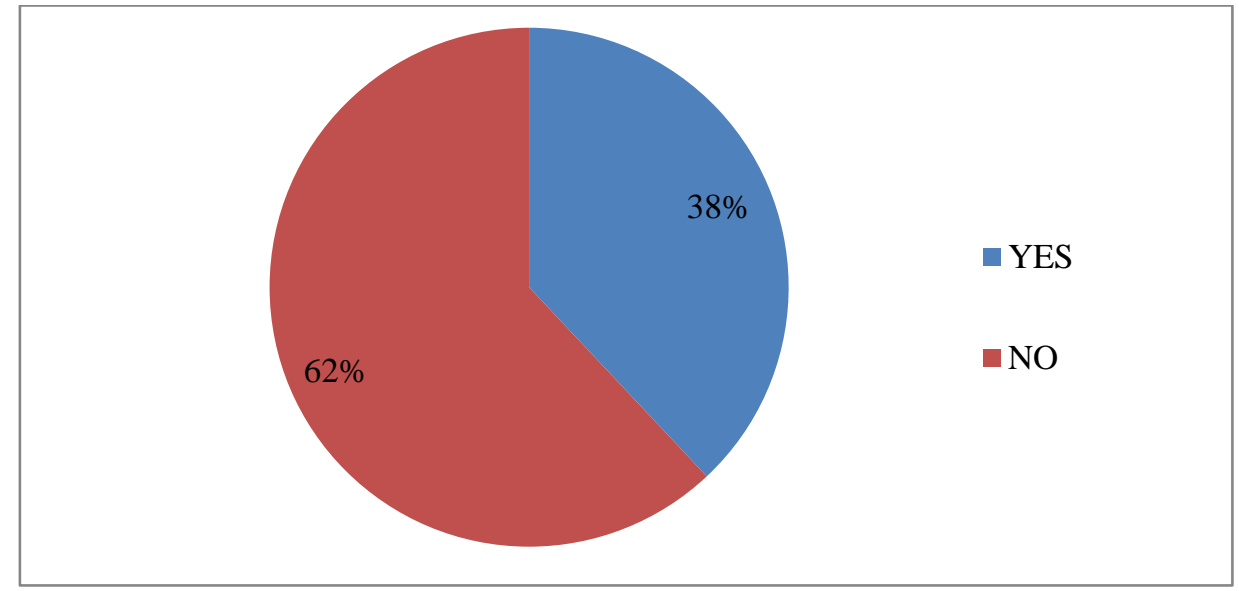

Figure 3. Complications reported after drinking raw milk.

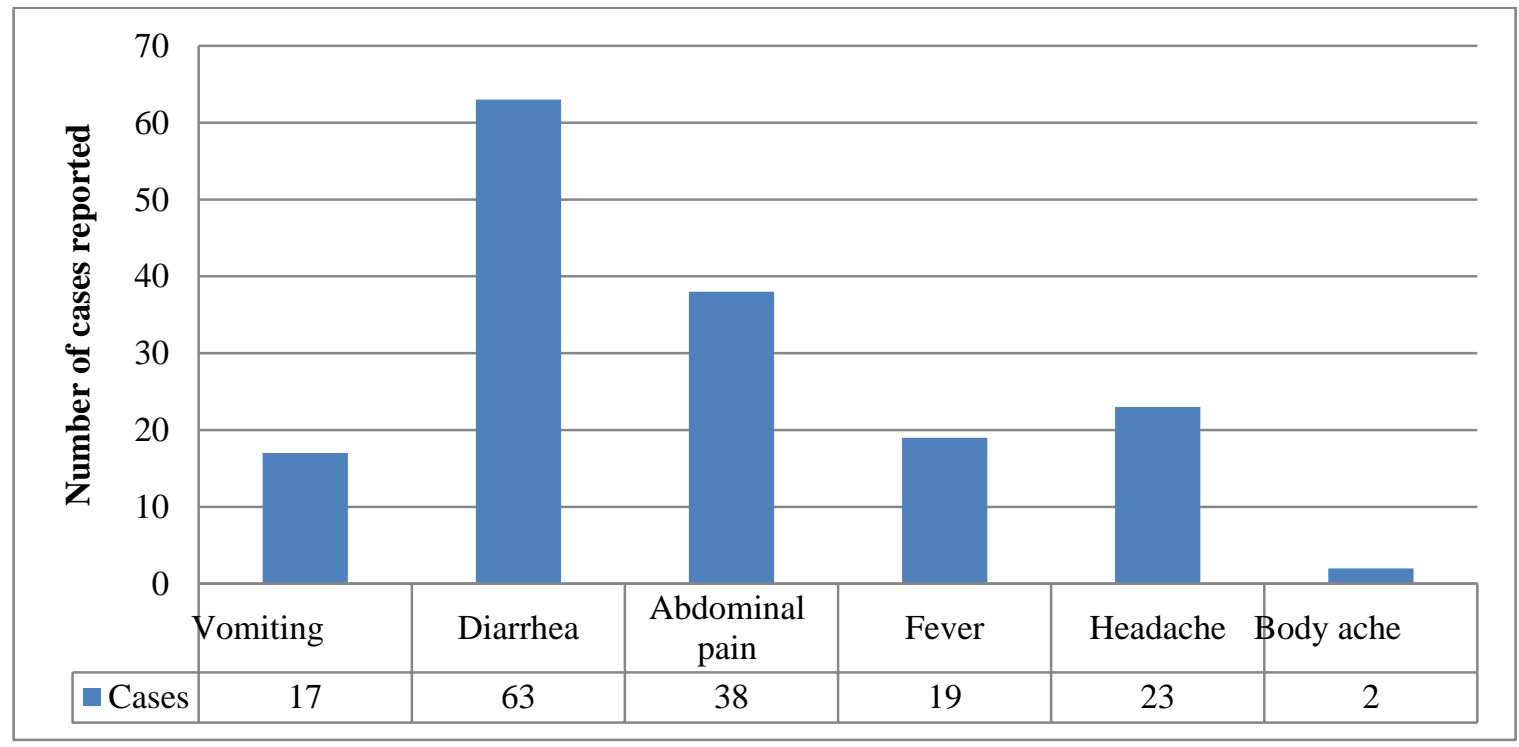

Figure 4. Symptoms Reported after drinking raw milk.

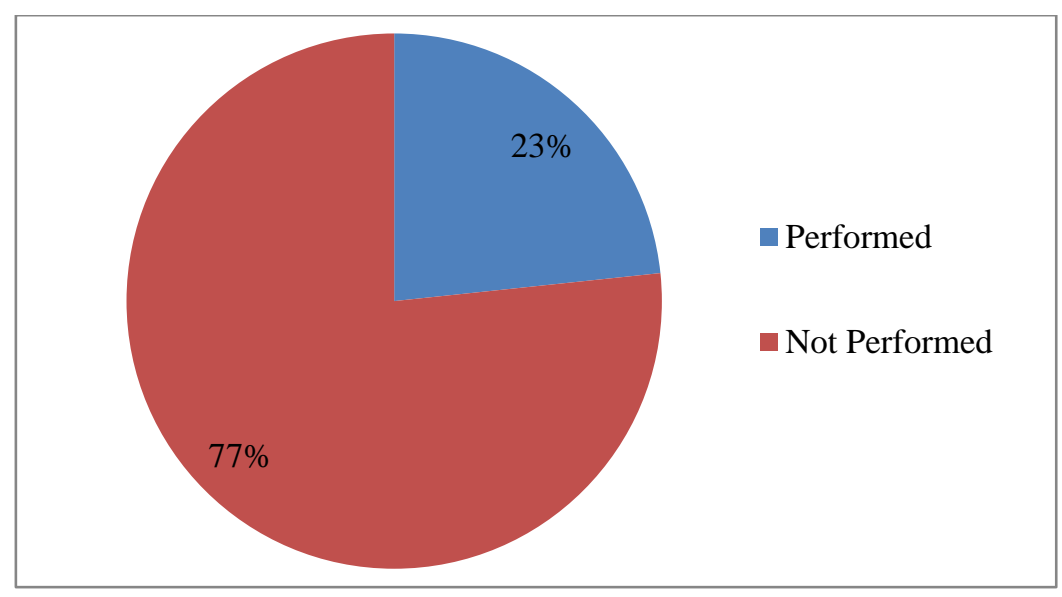

Figure 5. Farm level vaccination. 


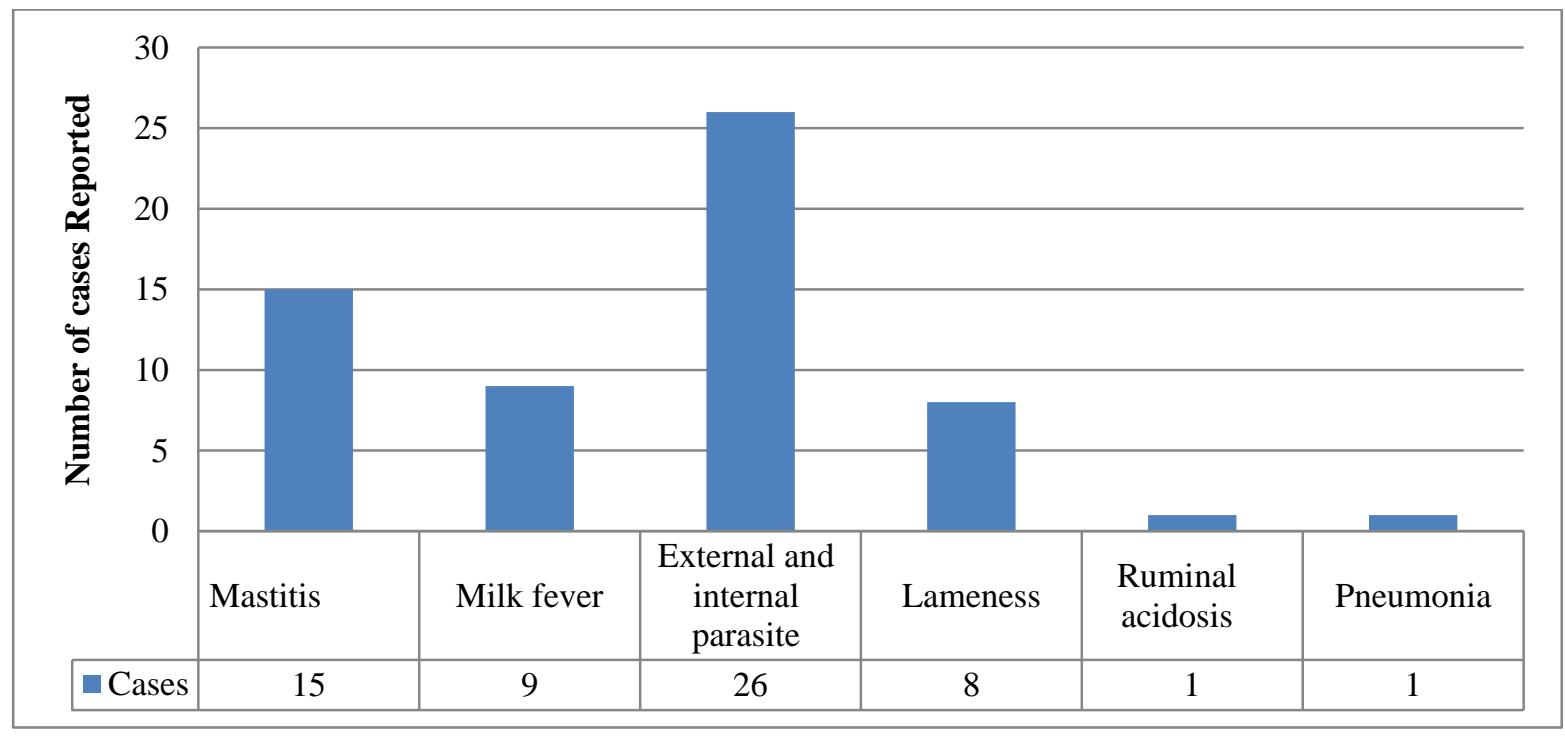

Figure 6. Farm level diseases history.

\section{Conclusions}

This study explained why people drink raw milk and how it endangers public health in Bangladesh's coastal regions. This assessment specifically shows that the consumption of raw milk poses a real and unavoidable health threat because of its possible contamination with pathogenic organism. It is therefore recommended to heat milk before consumption, especially when served to young children, pregnant women, or any person with immunosuppression. It is also identified that that the myth behind the drinking raw milk is scientifically not true. One way to approach this problem would be to develop educational outreach programmes for dairy producers, as well as for the general public, that focus on issues related to the consumption of raw milk. The government, private sector, and non-governmental organizations (NGOs) must all play a significant role in preventing people from engaging in such practices. In order to drastically reduce the number of raw milk associated outbreaks per year, country should not only deem it illegal to sell and consume raw milk, but should also ban cow-share programs. Once these measures are put into place and consumers fully realize the benefits and need of a pasteurized milk supply, milk-borne, and thus food-borne outbreaks swiftly decline.

\section{Conflict of interest}

None to declare.

\section{References}

Abebew D, K Belihu and G Zewde, 2014. Detection and determination of oxytetracycline and penicillin G antibiotic residue levels in Bovine bulk milk from Nazareth dairy farms in Ethiopia. Ethiop. Vet. J., 18: 1-15.

Al-Tahiri R, 2005. A comparison on microbial conditions between traditional dairy products sold in Karak and same products produced by modern dairies. Pak. J. Nutr., 4: 345-348.

Anakalo S and S Ase, 2004. Factors contributing to the occurance of antimicrobial drug residues in Kenyan milk. J. Food Prot., 67: 399-402.

Angela RK and B Paul, 2012. Motivation for unpasteurized milk consumption in Michigan, 2011. Food Prot.Trends., 32: 124-128.

Erica W, J Mitchell, S Reballato and D Fortuna, 2007. Raw milk and protection of public health. Can. Med. Assoc. J., 177: 721-723.

Food Standard Agency, 2018. Raw drinking milk consumer insight report. Available: https://www.food.gov.uk/sites/default/files/media/document/Raw\%20Drinking\%20Milk\%20Consumer\%20I nsight\%20Report\%202018.pdf

Gerard EM and MB Stephen, 2014. Survey to determine why people drink raw milk. Glob. Adv. Health. Med., 3: $19-24$.

Hafez A, 2019. Bangladesh coastal zone management status and future trends. Coast. Zone. Manag. J., 22: 1-6.

Hasan MA, MA Islam, MS Mahmud, ASMA Uddin and S Ahmed, 2015. Microbial analysis of raw and pasteurized milk from selected areas of Dinajpur, Bangladesh. Asian J. Med. Biol. Res., 1: 292-296. 
Hegarty H, MBO Sullivan, J Buckley and C Foley-Nolan, 2002. Continued raw milk consumption on farms: why? Commun. Dis. Public. Health., 5: 151-156.

International Farm Comparison Network, 2004. A review of milk production in Bangladesh with particular emphasis on small scale producers. Available: http://www.fao.org/3/bp227e/bp227e.pdf

Jayarao BM, SC Donaldson, BA Straley, AA Sawant, NV Hegde and JL Brown, 2006. A survey of food borne pathogens in bulk tank milk and raw milk consumption among farm families in Pennsylvania. J. Dairy Sci., 89: 2451-2458.

John AL, 2015. Raw milk consumption. Nutr., 50: 189-193.

Kathryn JB, W Martin, MI Sarah and A Sam, 2017. A 100 year review: microbiology and safety of milk handling. J. Dairy Sci., 100: 9933-9951.

Kivaria FM, JPTM Noordhuizen and AM Kapaga, 2006. Evaluation of the hygienic quality and associated public health hazards of raw milk marketed by smallholder dairy producers in the Dar es Salaam region, Tanzania. Trop. Anim. Health. Prod., 38:185-194.

Le LY, F Baron and M Gautier, 2003. Staphylococcus aureus and food poisoning. Genet. Mol. Res., 2: 63-76.

Mushfia M, A Jasmin, A Tasnia and MA Uddin, 2015. Isolation and quatification of microorganisms from some common milk products within Dhaka city, Bangladesh. S. J. Microbiol., 5: 13-17.

Nada S, D Ilija, T Igor, M Jelena and G Ruzica, 2012. Implication of food safety measures on microbiological quality of raw and pasteurized milk. Food Control, 25: 728-731.

Nathaly CP, AF Maria, F Wendy, AI Rodrigo and VBP Einar, 2017. Foodborne bacteria in dairy products: detection by molecular techniques. Int. J. Agric. Sci. Nat. Resour., 44: 215-229.

Oliver SP, BM Jayarao and RA Almeida, 2005. Foodborne pathogens in milk and the dairy farm environment: food safety and public health implications. Foodborne Pathog. Dis., 2: 115-129.

Omore A, T Lore, S Staal, J Kutwa, R Ouma, S Arimi and E Kang'ethe, 2005. Addressing the public health and quality concerns towards marketed milk in Kenya. Smallholder Dairy Project Research and Development, Report 3. ISBN 92-9146-168-7.

Orwa JD, JW Matofari, PS Muliro, 2016. Handling practices and microbial contamination sources of raw milk in rural and peri urban small holder farms in Nakuru Country, Kenya. Int. J. Livest. Prod., 8: 5-11.

Padma S and C Priyanka, 2012. Comparative assessment of milk borne pathogens and their antibacterial sensitivity. Int. J. Pharm. Sci. Res., 3: 3778-3782.

Pandey GS and GCS Voskuil, 2011. Manual on milk safety, quality and hygiene.Golden Valley Agricultural Research Trust, Zambia, pp. 1-52.

Revathi D, A Sindhura and N Arvind, 2012. Milk-borne infections. An analysis of their potential effect on the milk industry. Germs., 2: 101-109.

Sharma D, PK Sharma, and A Malik, 2011. Prevalence and antimicrobial susceptibility of drug resistant Staphylococcus aureus in raw milk of dairy cattle. Int. Res. J. Microbiol., 2: 466 - 470.

Shirima GM, J Fitzpatrick, S Cleaveland, DM Kambarage, R Kazwala, J Kunda and NP French, 2003. Participatory survey on zoonotic diseases affecting livestock keeping communities in Tanzania. J. Anim. Vet. Adv., 2: $253-258$.

Sivapalasingams S, CR Friedman, L Cohen and RV Tauxe, 2004. Fresh produce: a growing cause of outbreaks of foodborne illness in the United States, 1973 through 1997. J. Food Prot., 67: 2342-2353.

Swai ES and L Schoonman, 2011. Microbial quality and associated health risks of raw milk marketed in the Tanga region of Tanzania. Asian. Pac. J. Trop. Biomed., 1: 217-222.

Tahmina B, MM Islam, MC Sumy, MNA Mandal and GMN Uddin, 2013. Rapid estimation of quality of raw milk for its suitability for further processing in the dairy industries of Bangladesh. Int. J. Dairy. Sci., 8: 1-11.

Verraes C, G Vlaemynck, SV Weyenberg, GLD Zutter, M Sindic, M Uyttendaele and L Herman, 2015. A review of the microbiological hazards of dairy products made from raw milk. Int. Dairy. J., 50: 32-44.

Walter LH and KT Peter, 2011. Perspectives on immunoglobulins in colostrum and milk. Nutrients, 3: 442-474.

Yirsaw AW, 2004. Bacteriological quality of bovine milk in small holder dairy farms in Debrezeit, Ethiopia. Msc thesis, Faculty of Veterinary Medicine, Addis Ababa University, Ethiopia. 